


\begin{tabular}{ll}
\hline$\Omega$ & 0 \\
Ted Klok', & $\begin{array}{l}\text { 'Princess Amalia Children's } \\
\text { Clinic, Isala Klinieken, Zwolle }\end{array}$ \\
Adrian A. Kaptein², & $\begin{array}{l}\text { 'Unit of Psychology, Leiden } \\
\text { Paul L. P. Brand',3 }\end{array}$ \\
& $\begin{array}{l}\text { University Medical Centre, Leiden } \\
\text { 3UMCG Postgraduate } \\
\text { School of Medicine, } \\
\text { University Medical Center } \\
\text { and Groningen University, } \\
\text { Groningen, The } \\
\text { Netherlands }\end{array}$ \\
&
\end{tabular}

$\equiv$

P.L.P. Brand: Princess

Amalia Children's Clinic,

Isala Klinieken, PO Box

10400, Zwolle, 8000 GK,

The Netherlands
라

p.l.p.brand@isala.nl

\section{Improving adherence in paediatric respiratory disease}

\section{Educational aims}

๑ To review the evidence on determinants of adherence in children with chronic respiratory disease.

○ To discuss the "common sense model" as a method to understand medicationtaking behaviour in children.

$\odot$ To review the importance of illness perceptions and medication beliefs in determining adherence to maintenance medication in children with chronic respiratory disease.

๑ To present recommendations to optimise adherence through enhancing involvement of patients and parents in consultations of children with chronic respiratory disease.

\section{Summary}

In children with chronic respiratory disease, nonadherence to maintenance medication is common. Observational studies, however, show that good adherence can be achieved and maintained. This review will discuss the current state of the evidence on adherence and its determinants in children with chronic respiratory disease. It will highlight the importance of illness perceptions and medication beliefs as strong drivers of adherence, based on the common sense model of how people deal with a chronic illness. Exploring such cognitions by interested enquiry of the patient's perspective will help the clinician to identify and overcome barriers to adherence. When decisions on treatment are made according to the principle of shared decision making, concordance between patient and healthcare provider is aided, which improves adherence.
Statement of Interest None declared. 


\section{Introduction}

To the frustration of many physicians, patients do not always follow their doctor's advice. In fact, it is quite unusual for patients to do exactly what their doctor recommends them to do. Historically, such noncompliance was considered to be due to irrational behaviour or wilful ignoring of instructions, and patients deviating from doctors' instructions were described with terms such as "unreliable", "untrustworthy" and "faithless" [1]. This illustrates how doctors traditionally blamed the patients for not following expert advice. Over the past few decades, however, scientists have increasingly recognised that the patients' motives for deviation from their physician's recommendations are not irrational at all $[2,3]$. On the contrary, they make perfect sense to the one person to whom they matter - the patient. Patients, it turns out, have strong and persistent cognitions about their health, about illness, and about the best way to prevent and treat illness. These cognitions often strongly deviate from the medical model of the chronic illness, such as asthma (see "Perceptions about asthma and treatment with inhaled corticosteroids inconsistent with the medical model of asthma" box).

This recognition has encouraged research into how these patient perceptions of illness and medications may be explored, and perhaps even modified to concord with the medical state of the art. The focus of research in this area is, therefore, shifting from blaming the patient to examining what doctors can do to help patients take the optimal decisions about the treatment of their illness. In this article, we will review the evidence on "compliance" and "noncompliance" in general, with an emphasis on paediatric respiratory disease. This will form the basis for a set of simple principles which will help establish concordance between patient and healthcare provider, which increases the likelihood that patients will follow their advice.

\section{Terminology}

The traditional term of "noncompliance", along with its derogatory characterisation of patients, has largely been abandoned in research publications. In 2003, the World Health Organization (WHO) recommended to use the term "(non)adherence" instead, and presented a working definition of the
Perceptions about asthma and treatment with inhaled corticosteroids inconsistent with the medical model of asthma

"Most illnesses in children disappear by themselves."

"If you continue preventive medicine you can never find out whether the child can do without."

"I compare it with a sprained ankle: maybe you need crutches first, but for full recovery you have to walk without them."

"We wanted to find out how he would do without his medicine. Well, he was fine. So now we only give the medicine when he needs it."

"I don't want to burden my child with medicine when I am not sure it will help. With salbutamol, it is clear, but with fluticasone, you just have to assume that it works. And that is really difficult."

"It doesn't work as well when you use it on a daily basis."

"My kid's asthma is really not bad enough for steroids; I'd rather give him the blue inhaler a couple of times each day, you know, whenever he needs it."

"Daily medication prevents my child's body building resistance against asthma."

concept (see definitions box). Despite this attempt to standardise terminology, the concept of (non)adherence remains problematic for several reasons, as noted by STEINER and EARNEST [1]. "First, these words exaggerate the physician's control over the process of taking medications. Second, they imply that the patient must take the medication as prescribed to obtain benefit. Third, the terms "noncompliance" and "nonadherence" create a clinically unjustifiable distinction between persons who take all of their pills as prescribed and those who deviate from the prescription in any way. Finally, none of these terms accurately represents patients' motivations for choosing to take their medications a certain way." [1].

Despite these shortcomings, the term "adherence" is widely used in research studies, and we will use it in this review according to the WHO definition.

Two additional terms need to be defined, both of which are related to, but not synonymous with, adherence (see definitions box) 


\section{Definitions}

World Health Organization 2003 definition of adherence: the extent to which a person's behaviour, taking medication, following a diet, and/or executing lifestyle changes, corresponds with agreed recommendations from a healthcare provider. www.who.int/chp/ knowledge/publications/adherence_report/en/

Persistence: the act of continuing the treatment for the prescribed duration (the duration of time from initiation to discontinuation of therapy).

Concordance: the degree to which healthcare professional and patient agree on the treatment being recommended.

[3-5]. Many patients adhere to an initial treatment prescription, but fail to persist with it, for example because they do not receive a repeat prescription or because they are not followed-up. Nonpersistence is extremely common for inhaled corticosteroids (ICS) [6], in particular in primary care where scheduled follow-up visits for children with asthma are the exception rather than the rule [7, 8].

If patients and doctors explicitly agree on the choice, intensity, and duration of treatment (i.e. if they are in concordance), patients are more likely to adhere to the agreed treatment regimen, in particular if this takes their views, preferences and context into account $[5,9]$. Thus, while concordance is related to adherence [10], it does not ensure it, as there may be numerous other issues interfering with adherence [11].

\section{Nonadherence: is it relevant?}

It has been well documented for a range of acute and chronic illnesses that nonadherence has a major impact on the efficacy of treatment and health outcomes for patients [12]. In childhood asthma, nonadherence has been known for decades to be related to increased symptoms, a higher risk of hospitalisation for asthma exacerbations and asthma deaths [13, 14]. Nonadherence has been recognised as an important cause of problematic severe asthma [15], although the extent to which problematic severe asthma can be explained by nonadherence is, as yet, unknown. Nevertheless, adherence is an issue worth exploring in every follow-up visit of children with a chronic (respiratory) disease, in particular when the disease remains poorly controlled despite the prescription of control medication.

\section{Nonadherence: the scope of the problem}

Contrary to what many people would instinctively think, nonadherence does not appear to be related to severity of disease $[1,2]$. In a cohort of children with very problematic severe asthma referred to a national tertiary care referral centre in the UK, medication was either absent or out-of-date in $23 \%$ of home visits by an asthma nurse [16].

As a rule of thumb, patients take approximately half of the medication prescribed to them $[1,2]$. In studies in children with asthma, where adherence was measured electronically by logging devices recording each actuation of the inhaler, median adherence rates usually vary between $30 \%$ and $70 \%$ of the total number of doses prescribed, with large variations between individual patients [17-21]. We recently reported a median adherence of $92 \%$ in 2-6-year-old children with asthma over a period of 3 months [22], illustrating that good adherence can be achieved in children with chronic respiratory disease [23].

\section{Measuring adherence}

As a rule, patients (or their parents) overestimate their own (or their child's) adherence to daily maintenance medication [24, 25]. Therefore, parental or patient reporting of adherence is unreliable [26]. Incidentally, the same applies for physicians' assessment of adherence in the patients to whom they provide medical care [24]. It has been suggested that enquiring about medication use, in an understanding and non-confrontational manner (e.g. "Many people find it difficult to take their medication daily. What's this like for you?"), would provide a reasonable estimate of adherence [27], but very few studies have actually examined this. A recent study would suggest that asking parents about missed doses and about trials off medication at their own initiative could help in identifying nonadherence [24].

Pharmacy refill rates for prescriptions, although easily available, are similarly unreliable 
[26], because they only reflect whether the medication has been picked up from the pharmacy, not whether it has actually been taken. Pharmacokinetic and pharmacodynamic monitoring of drug effects, while highly accurate and reliable, is too invasive and costly to be used in large-scale clinical studies. Weighing used metered dose inhaler (MDI) canisters, or using the built-in counter devices of dry powder inhalers (DPIs) to calculate adherence is reasonably accurate, although "dumping" (emptying the device before returning it to the doctor to mimic good adherence) cannot be detected this way.

Electronic monitoring has emerged as the most accurate, valid and cost-effective method of monitoring adherence [28]. A number of electronic devices have been developed (fig. 1). The Doser device only counts the number of actuations and, therefore, does not detect dumping. The other devices record date and time of each actuation on a microchip which

a)
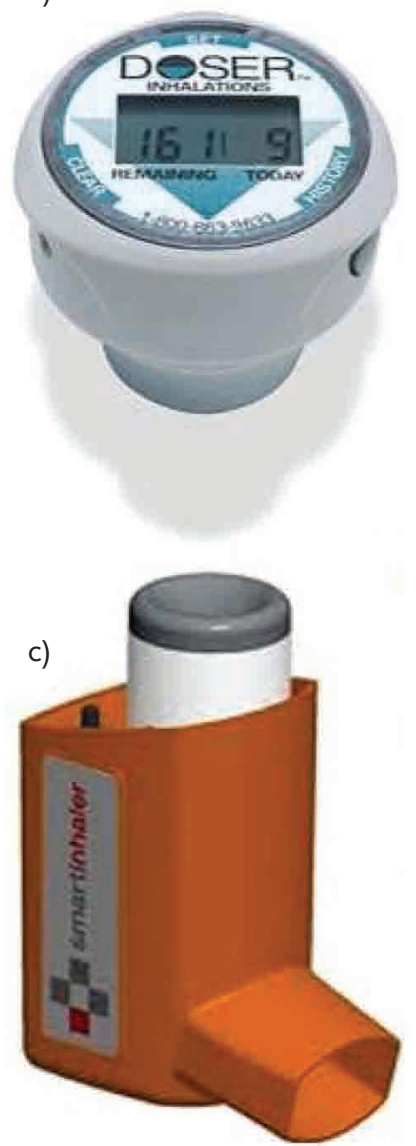

can store data for 4-6 weeks; these devices are able to detect dumping [28]. Three devices can monitor adherence of medication delivered by MDI (either with or without a spacer), and one is suitable for monitoring adherence to medication from the Diskus DPI, the SmartDisk (fig. 1). All electronic devices suffer to some extent from mechanical and electronic failures, but have otherwise been well validated [28]. There is now consensus in the literature that such electronic devices are the recommended method to measure adherence reliably, both in clinical practice and in research $[26,28]$.

\section{A useful model to understand medication taking behaviour}

Recent research lends support to a theoretical model that explains differences between

b)
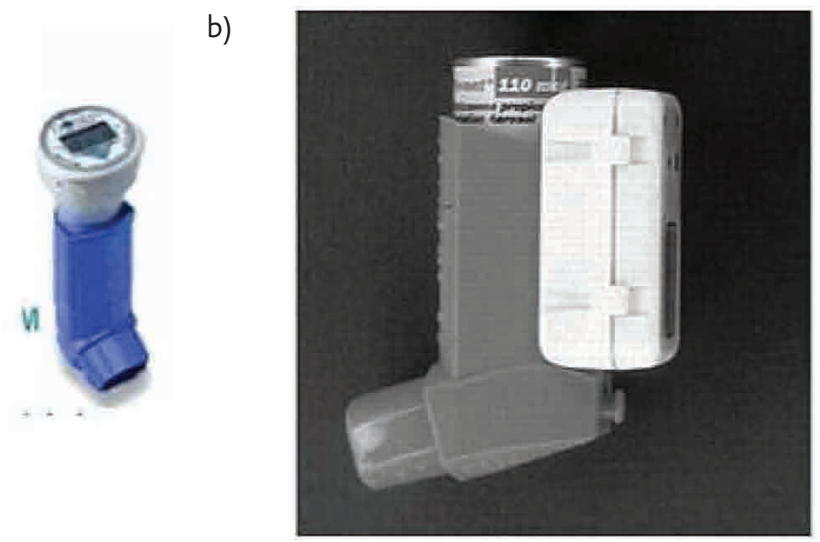

d)

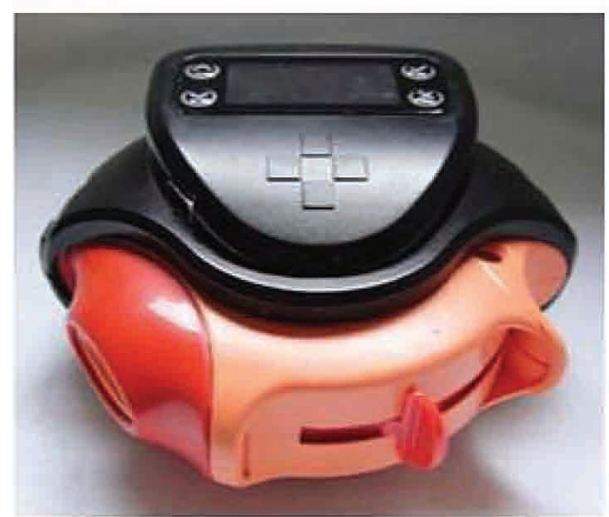

Figure 1

Electronic adherence monitoring devices suitable for use in clinical practice and research. a) Doser, b) MDILog, c) Smartinhaler and d) SmartDisk. 
patients in the self-management of their chronic illness, including differences in their adherence to its treatment. This common sense model states that people try and make sense of a threat to their health in order to try and control the threat [29]. A patient with asthma who perceives the asthma to have an episodic nature will not perceive the necessity of taking preventive medication. This "no symptoms, no asthma" behaviour will lead to inadequate control of asthma [30]. By contrast, a patient who perceives the asthma to be a chronic condition that necessitates maintenance medication will be more likely adhere to medication use [31], and will have a higher chance of controlling their asthma. Patients create their own personal cognitive representation of their illness, which include beliefs about what may have caused the illness, the consequences the illness will have on their lives, how long the illness will last, and whether or not it is controllable or curable. In parallel, they also develop emotional responses to the threat. The cognitive and emotional representations of symptoms and illnesses are called illness perceptions [29]. These illness perceptions are shaped by early childhood experiences in which children learn how to respond to sickness and pain from caregivers and other influential people in their environment. In addition, public images (television, internet and the lay press) and the stories of parents, teachers and physicians play a role in shaping these experiences. Illness perceptions, therefore, are more strongly influenced by cultural, social and psychological factors than by the medical severity of the illness, or by intellectual capacity or socioeconomic class of the parents [3]. Cognitions about the benefits and harms of therapy are developed in a similar way. A schematic representation of the relationship between illness perceptions, medication beliefs and adherence is presented in figure 2 [3]. There is now good and consistent evidence from a range of chronic conditions [32, 33], including childhood asthma [22, 34, 35], that illness perceptions and, in particular, medication beliefs are strongly associated with (non)adherence. These cognitions of illness and treatment are stronger determinants of adherence than factors associated with the patient (such as age, sex or socioeconomic status), the disease (severity, chronicity) or the knowledge that the patient has about the disease.
The latter explains why providing information (patient education) by itself is, therefore, not successful in improving adherence in paediatric chronic disease [36]. Only when the education is tailored to explore and modify illness perceptions and medication beliefs can it be expected to have a beneficial effect on adherence [29].

\section{Barriers to adherence}

Although it is becoming increasingly clear that illness perceptions and medication beliefs are the strongest patient-related barriers to adherence, a number of other treatment-, physician- and patient-related barriers have been reported to be associated with (non)adherence (see barriers to adherence box) [37].

The more complex a treatment schedule is the less likely the patient is to adhere to it [38]. However, even with very complex maintenance treatment schedules, for example for patients with HIV or tuberculosis, excellent adherence to such treatment is possible when the importance

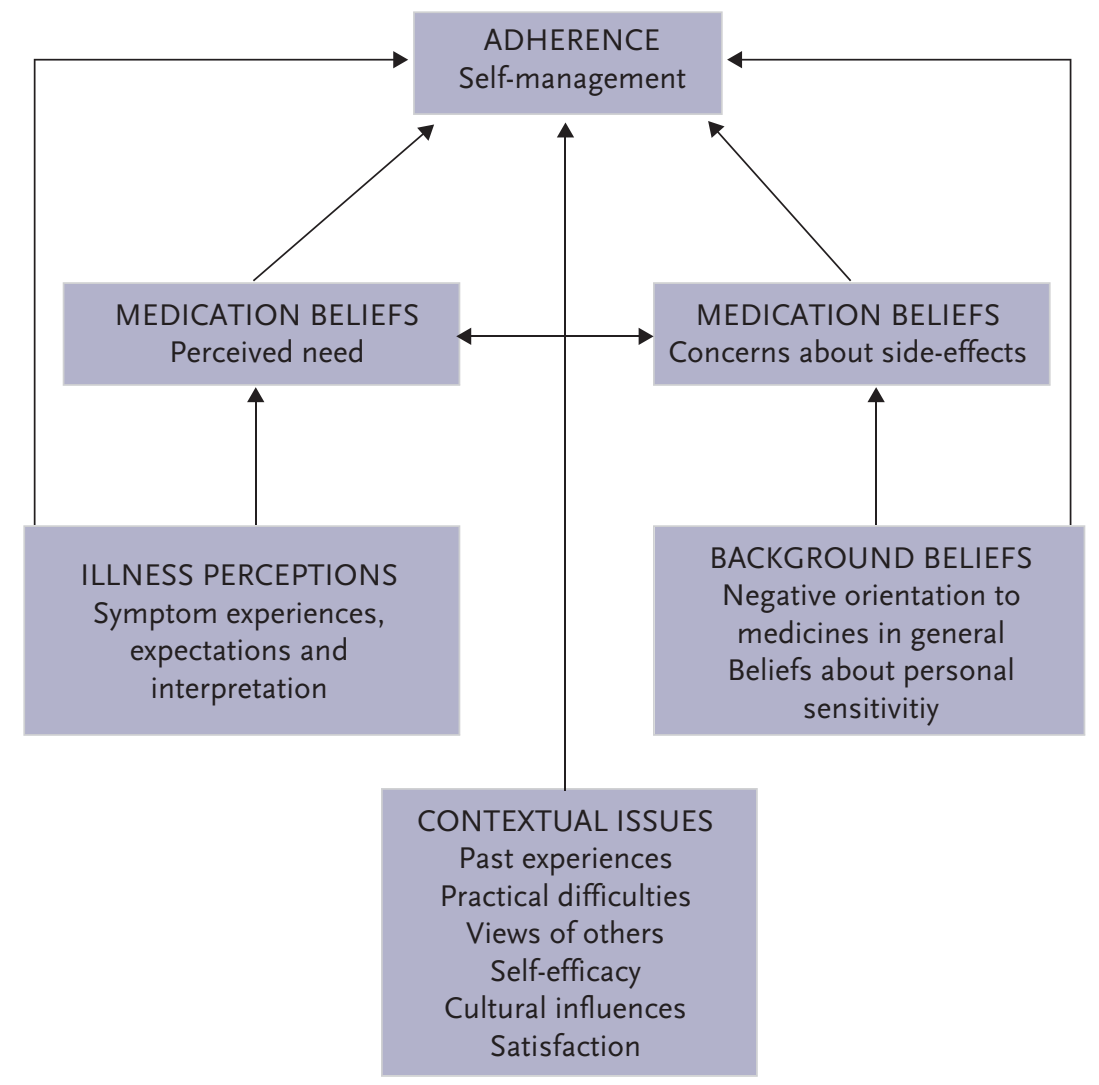

Figure 2

Horne's extension of the common sense model, showing the relationship between illness perceptions, medication beliefs, and adherence. Reproduced from [3] with permission from the publisher. 
of strict adherence has been discussed and agreed, including a balanced discussion of the pros and cons of treatment (i.e. when the medication beliefs of patients have been addressed). The difference in immediate effect between bronchodilators and ICS may help to explain why many patients with asthma over rely on bronchodilators to control their symptoms, at the expense of daily ICS use [39]. Adverse effects rank among the treatment-related barriers, while the (usually much stronger) perceived potential side-effects represent medication beliefs and patient-related barriers. Cost and reimbursement of medication may play a major role in adherence, in particular in patients with poor or absent health insurance [39].

Physicians who do not follow-up their patients regularly cannot be expected to build a strong therapeutic alliance, which is considered to be essential in the long-term management of paediatric chronic respiratory disease (www.ginasthma.org). Patients want their physician to be easily available for consultation and they prefer to see the same physician at every follow-up visit [37]. They also want their physician to show empathy, to be interested in their views, concerns and preferences [40]. Unidirectional, top-down information or advice ("you really should give up smoking now; how many times have I told you it's bad for Jimmy's health?") is largely ineffective [41]. What does help is exploring how patients feel about their disease and about taking medication on a daily basis (i.e. exploring their illness perceptions and medication beliefs), and tailoring the information provided on these cognitions [29]. Regular follow-up with the same empathic physician helps to allow this essential process to take place.

In addition to illness perceptions and medication beliefs, a number of other patientrelated barriers to adherence may be encountered. Basic knowledge of the disease and its treatment is required to help patients to take the medication as prescribed, but we emphasise once again that such education per se does not improve adherence [36], but that it needs to be tailored to the information needs of patients. Families struggling with serious psychosocial issues, such as poverty, relationship problems or psychiatric illness, will face major problems in managing any chronic condition [42, 43].

\section{What can the healthcare professional do to improve adherence?}

The interventions physicians can employ to improve adherence should follow logically from the evidence reviewed above. Because adherence is a multidimensional construct, in which poor understanding of disease or treatment is only one of the many potential

\section{Barriers to adherence}

\begin{tabular}{|c|c|c|}
\hline Treatment-related barriers & Clinician-related barriers & Patient-related barriers \\
\hline Complex treatment schedule & $\begin{array}{l}\text { Difficulties in scheduling } \\
\text { appointments }\end{array}$ & $\begin{array}{l}\text { Poor understanding of disease } \\
\text { or treatment }\end{array}$ \\
\hline $\begin{array}{l}\text { Lack of an immediately } \\
\text { discernible beneficial effect }\end{array}$ & $\begin{array}{l}\text { Lack of empathy and interest } \\
\text { from clinician }\end{array}$ & $\begin{array}{l}\text { Lack of trust in healthcare } \\
\text { professionals }\end{array}$ \\
\hline Adverse effects & Rotating physicians & $\begin{array}{l}\text { Psychological problems or } \\
\text { psychiatric illness }\end{array}$ \\
\hline \multirow[t]{2}{*}{$\begin{array}{l}\text { Cost, reimbursement } \\
\text { problems }\end{array}$} & $\begin{array}{l}\text { Physician provides information, } \\
\text { but leaves little room for } \\
\text { questions and concerns }\end{array}$ & $\begin{array}{l}\text { Social issues (poverty, lack of } \\
\text { healthcare insurance, lack of } \\
\text { family (medication taking) } \\
\text { routines) }\end{array}$ \\
\hline & & $\begin{array}{l}\text { Illness perceptions and } \\
\text { medication beliefs hampering } \\
\text { motivation to adhere }\end{array}$ \\
\hline
\end{tabular}


The five E's of ensuring optimal adherence

\author{
Ensure follow-up \\ See patients and their parents repeatedly \\ Helps to build trust and partnership \\ Explore patient's views, beliefs and preferences \\ Explore illness perceptions and medication beliefs \\ Examine patient's context, views, and preferences \\ Discuss potential barriers to adherence (see barriers to adherence box) \\ Invite questions, comments, remarks

\section{Express Empathy} \\ Positive, caring attitude \\ Use active listening techniques \\ Provide information tailored to patient's needs

\section{Exercise shared decision making} \\ Aim for concordance (see definitions box) \\ Take patient's views and preferences into account \\ Agree on treatment and action plan with patient

\section{Evaluate} \\ During follow-up visits: evaluate success of treatment \\ Discuss adherence in non-judgmental fashion \\ Offer help when needed to overcome barriers
}

\section{Self-evaluation questions}

1. What is the key difference between adherence and persistence?

a. Adherence and persistence are synonyms

b. Adherence relates to medication taking as prescribed, persistence relates to medication taking for the duration as prescribed

c. Adherence relates to medication taking, persistence to the disease itself

2. Which of the following is the most important determinant of adherence to maintenance medication in children with chronic respiratory disease?

a. socio-economic status of the parents

b. knowledge of the disease and its treatment

c. severity of the disease

d. medication beliefs

3. Illness

perceptions are shaped by:

a. early childhood influences

b. the internet and

lay press

c. paternal illness

behaviour

d. all of the above 
4. When faced with a child whose parents fail to adhere to the maintenance medication prescribed, which approach is most likely to improve adherence?

a. repeated

education and

information

b. appealing to the parents' sense of guilt

c. exploring parental medication beliefs

d. simplifying treatment schedule to once-daily dosing showed that shared decision making is associated with improved adherence [50].

The final step to ensure adherence is to evaluate the treatment and its success during further follow-up. Gentle probing of how the patient feels about taking medication and any problems the patient and parents may encounter in using the medication as agreed, may help to identify barriers to adherence, and opens up an exploration of the help required to overcome them.

\section{Conclusions}

Although nonadherence in paediatric chronic respiratory disease is common, empirical evidence strongly suggests that good adherence can be achieved. To understand a patient's medication-taking behaviour, the extended common sense model, comprising both illness perceptions and medication beliefs, is useful. In addition to these cognitions, a number of other barriers may hamper adherence. By exploring illness perceptions and medication beliefs, and by showing a genuine interest in the patient's context, views and preferences, these barriers can be identified, and tailored selfmanagement education and help offered to overcome them. Rather than prescribing therapy, physicians can weigh the pros and cons of different treatment options with the patient and the parent, aiming at shared decision making of a mutually agreed treatment plan. These principles have been shown to be associated with improved adherence and can, therefore, be recommended for general use. Although this requires specific communication skills, these can be learned and mastered [51].

\section{References}

1. Steiner JF, Earnest MA. The language of medicationtaking. Ann Intern Med 2000; 132: 926-930.

2. Osterberg L, Blaschke T. Adherence to medication. $N$ Engl J Med 2005; 353: 487-497.

3. Horne R. Compliance, adherence, and concordance: implications for asthma treatment. Chest 2006; 130: Suppl. 1, 65S-72S.

4. Cramer JA, Roy A, Burrell A, et al. Medication compliance and persistence: terminology and definitions. Value Health 2008; 11: 44-47.

5. Stevenson FA, Cox K, Britten N, et al. A systematic review of the research on communication between patients and health care professionals about medicines: the consequences for concordance. Health Expect 2004; 7: 235-245

6. Hasford J, Uricher J, Tauscher M, et al. Persistence with asthma treatment is low in Germany especially for controller medication - a population based study of 483051 patients. Allergy 2010; 65: 347-354.

7. Kuethe MC, Vaessen-Verberne AA, Bindels PJ, et al. Children with asthma on inhaled corticosteroids managed in general practice or by hospital paediatricians: is there a difference? Prim Care Respir J 2010; 19: 62-67.

8. Jonsson M, Egmar AC, Kiessling A, et al. Adherence to national guidelines for children with asthma at primary health centres in Sweden: potential for improvement. Prim Care Respir J 2012; 21: $276-282$.

9. Bokhour BG, Cohn ES, Cortés DE, et al. Patterns of concordance and non-concordance with clinician recommendations and parents' explanatory models in children with asthma. Patient Educ Couns 2008; 70: $376-385$

10. Riekert KA, Butz AM, Eggleston PA, et al. Caregiverphysician medication concordance and undertreatment of asthma among inner-city children. Pediatrics 2003; 111: e214-e220.
11. DiMatteo MR, Haskard-Zolnierek KB, Martin LR. Improving patient adherence: a three-factor model to guide practice. Health Psychology Review 2012; 6: 74-91.

12. Dimatteo MR, Giordani PJ, Lepper HS, et al. Patient adherence and medical treatment outcomes: a metaanalysis. Med Care 2002; 40: 794-811.

13. Milgrom H, Bender B, Ackerson L, et al. Noncompliance and treatment failure in children with asthma. J Allergy Clin Immunol 1996; 98: 1051-1057.

14. Robertson CF, Rubinfeld AR, Bowes G. Pediatric asthma deaths in Victoria: the mild are at risk. Pediatr Pulmonol 1992; 13: 95-100.

15. Bush A, Saglani S. Management of severe asthma in children. Lancet 2010; 376: 814-825.

16. Bracken $M$, Fleming $L$, Hall $P$, et al. The importance of nurse-led home visits in the assessment of children with problematic asthma. Arch Dis Child 2009; 94: 780-784.

17. Bender B, Wamboldt FS, O'Connor SL, et al. Measurement of children's asthma medication adherence by self report, mother report, canister weight, and Doser CT. Ann Allergy Asthma Immunol 2000; 85: 416-421.

18. Fiese $\mathrm{BH}$, Wamboldt FS. Tales of pediatric asthma management: family-based strategies related to medical adherence and health care utilization. J Pediatr 2003; 143: 457-462.

19. Gibson NA, Ferguson AE, Aitchison TC, et al. Compliance with inhaled asthma medication in preschool children. Thorax 1995; 50: 1274-1279.

20. Burgess SW, Sly PD, Morawska A, et al. Assessing adherence and factors associated with adherence in young children with asthma. Respirology 2008; 13: 559-563.

21. Jentzsch NS, Camargos P, Sarinho ES, et al. Adherence rate to beclomethasone dipropionate and 
the level of asthma control. Respir Med 2012; 106: 338-343.

22. Klok T, Kaptein AA, Duiverman EJ, et al. High inhaled corticosteroids adherence in childhood asthma: the role of medication beliefs. Eur Respir J 2012; 40: 1149-1155.

23. Scott $\mathrm{L}$, Morphew T, Bollinger ME, et al. Achieving and maintaining asthma control in inner-city children. J Allergy Clin Immunol 2011; 128: 56-63.

24. Schultz A, Sly PD, Zhang G, et al. Usefulness of parental response to questions about adherence to prescribed inhaled corticosteroids in young children. Arch Dis Child 2012; 97: 1092-1096.

25. Krishnan JA, Bender BG, Wamboldt FS, et al. Adherence to inhaled corticosteroids: an ancillary study of the Childhood Asthma Management Program clinical trial. J Allergy Clin Immunol 2012; 129: 112-118.

26. Jentzsch NS, Camargos PA, Colosimo EA, et al. Monitoring adherence to beclomethasone in asthmatic children and adolescents through four different methods. Allergy 2009; 64: 1458-1462.

27. Stephenson BJ, Rowe BH, Haynes RB, et al. The rational clinical examination. Is this patient taking the treatment as prescribed? JAMA 1993; 269: 2779-2781.

28. Ingerski LM, Hente EA, Modi AC, et al. Electronic measurement of medication adherence in pediatric chronic illness: a review of measures. J Pediatr 2011; 159: 528-534.

29. Kaptein AA, Klok T, Moss-Morris R, et al. Illness perceptions: impact on self-management and control in asthma. Curr Opin Allergy Clin Immunol 2010; 10: 194-199.

30. Halm EA, Mora P, Leventhal H. No symptoms, no asthma: the acute episodic disease belief is associated with poor self-management among inner-city adults with persistent asthma. Chest 2006; 129: 573-580.

31. Klok T, Brand PL, Bomhof-Roordink $\mathrm{H}$, et al. Parental illness perceptions and medication perceptions in childhood asthma, a focus group study. Acta Paediatr 2011; 100: 248-252.

32. Horne R, Weinman J. Patients' beliefs about prescribed medicines and their role in adherence to treatment in chronic physical illness. J Psychosom Res 1999; 47: 555-567.

33. Jackson CA, Clatworthy J, Robinson A, et al. Factors associated with non-adherence to oral medication for inflammatory bowel disease: a systematic review. Am J Gastroenterol 2010; 105: 525-539.

34. McQuaid EL, Everhart RS, Seifer R, et al. Medication adherence among latino and non-latino white children with asthma. Pediatrics 2012; 129: e1404-e1410.

35. Drotar D, Bonner MS. Influences on adherence to pediatric asthma treatment: a review of correlates and predictors. J Dev Behav Pediatr 2009; 30: 574-582.

36. Dean AJ, Walters J, Hall A. A systematic review of interventions to enhance medication adherence in children and adolescents with chronic illness. Arch Dis Child 2010; 95: 717-723.

37. Bender BG. Overcoming barriers to nonadherence in asthma treatment. J Allergy Clin Immunol 2002; 109: Suppl. 6, S554-S559.

38. Bender BG, Bender SE. Patient-identified barriers to asthma treatment adherence: responses to interviews, focus groups, and questionnaires. Immunol Allergy Clin North Am 2005; 25: 107-130.

39. Celano MP, Linzer JF, Demi A, et al. Treatment adherence among low-income, African American children with persistent asthma. J Asthma 2010; 47: 317-322.

40. Mauksch LB, Dugdale DC, Dodson S, et al. Relationship, communication, and efficiency in the medical encounter: creating a clinical model from a literature review. Arch Intern Med 2008; 168: 1387-1395.

41. Lask B. Motivating children and adolescents to improve adherence. J Pediatr 2003; 143: 430-433.

42. Bender B, Milgrom H, Rand C, et al. Psychological factors associated with medication nonadherence in asthmatic children. J Asthma 1998; 35: 347-353.

43. Fiese BH, Wamboldt FS, Anbar RD. Family asthma management routines: connections to medical adherence and quality of life. J Pediatr 2005; 146: $171-176$.

44. Brouwer AFJ, Brand PLP. Asthma education and monitoring: what has been shown to work. Paediatr Respir Rev 2008; 9: 193-199.

45. Klok T, de Groot EP, Brouwer AFJ, et al. Follow-up of children with asthma, In Carlson K-H, Gerritson J, eds. Paediatric Asthma. Eur Respir Mongr 2012; 56: 210-223.

46. Hederos CA, Janson S, Hedlin G. Six-year follow-up of an intervention to improve the management of preschool children with asthma. Acta Paediatr 2009; 98: 1939-1944.

47. Gore C, Johnson RJ, Caress AL, et al. The information needs and preferred roles in treatment decision-making of parents caring for infants with atopic dermatitis: a qualitative study. Allergy 2005; 60: 938-943.

48. Di Blasi Z, Harkness E, Ernst E, et al. Influence of context effects on health outcomes: a systematic review. Lancet 2001; 357: 757-762.

49. Stiggelbout AM, Van der Weijden T, De Wit MP, et al. Shared decision making: really putting patients at the centre of healthcare. BMJ 2012; 344: e256.

50. Wilson SR, Strub P, Buist AS, et al. Shared treatment decision making improves adherence and outcomes in poorly controlled asthma. Am J Respir Crit Care Med 2010; 181: 566-577.

51. Bensing JM, Deveugele M, Moretti F, et al. How to make the medical consultation more succesful from a patient's perspective? Tips for doctors and patients from lay people in the United Kingdom, Italy, Belgium and the Netherlands. Patient Educ Couns 2011; 84: 287-293.
Suggested answers

1. b.

2. d.

3. d.

4. c. 